\title{
Research on Electrical Technology Schemes for Construction of Charging and Swapping Stations in Alpine Regions
}

\author{
Yuxing $\mathrm{Li}^{1}$, Hao $\mathrm{Wu}^{2}$, Yu $\mathrm{Shi}^{1}$, Hao $\mathrm{Li}^{1}$, Xuefeng $\mathrm{Gao}^{1}$, Yeyang $\mathrm{Zhu}^{3}{ }^{3}$ \\ ${ }^{1}$ State Grid Economic And Technical Research Institute Of Jilin Electric Power., LTD \\ ${ }^{2}$ Hangzhou Power Supply Company of State Grid Zhejiang Electric Power Company \\ ${ }^{3}$ University of Southern California
}

\begin{abstract}
Influenced by policies, resources and environmental factors, the development of electric vehicles has been in an upsurge in these years. Compared with conventional vehicles, electric buses better meet the needs of environmental protection and contribute more to environmental well-being. The State Grid Liaoning Electric Power Supply Company, to promote the use of electric buses, has built many charging and swapping stations in Dalian, which has significant impact on the application of electric buses. To meet the needs of increasing electric buses, this paper mainly discusses the design schemes of the charging and swapping stations of Youyi Street in Dalian, and finally chooses the scheme of "entering the station for swapping-decentralized charging" through comparison in the design.
\end{abstract}

\section{PREFACE}

With the depletion of fossil fuels in recent years, the environment is heavily polluted, and in particular, the increase in carbon dioxide emissions leads to the greenhouse effect. Among them, the biggest pollutant is automobile emissions. For this reason, China has vigorously invested in the emerging industry of electric vehicles to alleviate environmental pressure. According to statistics released by the Public Security Department in 2019, the retain number of new energy vehicles reached 3.81 million, and the retain number of pure electric vehicles was 3.1 million. As charging facilities are an important factor in promotion of electric vehicles, China is actively setting up charging facilities, and various provinces and cities are vigorously building charging infrastructure and expanding the use of electric buses. Based on this background, this paper focuses on discussing the electrical technology scheme for the construction of charging and swapping stations in alpine regions. ${ }^{[1]}$

\section{PROJECT SCALE}

As buses are an important part of urban transportation and also a means of transportation commonly used by residents in their daily life, at present, the government vigorously promotes the use of electric buses. Therefore, this paper takes Dalian as the research object, and chooses Dalian Youyi Street to design the charging pile and station system, which includes power supply and distribution system, charging pile electric system and photovoltaics system. The power distribution system is mainly to provide current energy to ensure its capacity to meet the needs of all-day battery charging, as well as the power demands of lighting equipment and monitoring equipment. The charging and swapping system is the core of the charging and swapping power station, which is responsible for the battery power supply of electric vehicles. The application of the monitoring system can realize real-time monitoring and recording of the situation of the power station and ensure the safe and stable operation of the charging station. ${ }^{[2]}$

\section{SERVICE OBJECT}

\subsection{Application Features of Electric Buses}

During the design of charging stations in Youyi Street, 50 pure electric buses are taken as the power supply objects of the power supply station. Every day, the bus route and service time are fixed. If the bus is charged only once a day, it will be difficult to support its all-day operation. The bus needs to travel $100-200 \mathrm{~km}$ each day and depart at a fixed interval. The service time is set between 8 and 12 hours. Each bus must strictly follow the system scheduling frequency. Different from ordinary electric vehicles, the battery capacity required by the electric bus is relatively large.

\subsection{Charging and Swapping Mode}

According to the operation mechanism, pure electric vehicles currently have five power supply modes. The specific modes are as follows:

(1) The vehicle can be connected to the charger once entering the station and realize "charging the whole

\footnotetext{
${ }^{*}$ Corresponding author: yeyangzh@usc.edu
} 
vehicle in the station". If the electric bus is charged in this way, it will take a long time.

(2) After the electric bus has been running for a certain number of shifts, the whole vehicle is charged, and the way of "centralized charging mode for the whole vehicle" is often carried out at night after the bus stops running. ${ }^{[3]}$

(3) The third charging mode is a combination of the above two charging modes. After the electric bus enters the station, it is first charged by the storage battery. Although the charging process cannot fully charge the electric bus, it can make up for the needs so that it can run continuously. The electric bus needs to be uniformly charged at night to replenish the remaining power.

(4) Electric buses can also adopt the swapping method. At present, the swapping method can be subdivided into two types. The first type is that after the run-down batteries are replaced, they are charged uniformly and centrally. The charging time is generally at night, which can not only realize charging but also reduce the charging cost. However, at the same time, this method requires a plurality of high-power chargers to work, and a large amount of battery back-up needs to be added in order to meet the demand. The other type is to charge the replaced battery in a decentralized mode and use one day for decentralized charging. ${ }^{[4]}$ It is not necessary to completely charge within a certain period, which may result in heavy load. At the same time, this mode can reduce the reserve of the swapping station and cut down the instantaneous charging load of the charging station.

Based on the above-mentioned charging methods, the combination of battery replacement and decentralized charging mode is finally selected, which ensures not only the safety of charging but also the economic costs in the charging process. This method can be generalized to some extent, especially for public transportation systems with dense and frequent departure times.

\subsection{Battery Type Selection}

The rechargeable batteries of pure electric buses are mostly storage batteries. Due to the variety in charging currently, they have great differences. By comparing lead-acid battery, nickel-cadmium battery, nickelhydrogen battery and lithium battery, finally, the lithium battery is selected. Because of the high power, high energy, and high cycle life, it is widely favored in the field of electric vehicles. At present, the application of lithium battery in electric bus is an important part of scholars' research. However, lithium batteries can be further subdivided into lithium manganate batteries, ternary material lithium batteries and ferrous phosphate lithium batteries according to their material characteristics. ${ }^{[5]}$ After comparing the three types of lithium batteries, the price factor is finally taken as the priority, and lithium manganate batteries are selected. Lithium manganate batteries have already met the current basic power demands of electric buses.

\section{ENGINEERING DESIGN PLAN}

\subsection{Design of Power Supply and Distribution System}

According to the design requirements of electric vehicle's charging and power supply system, the load rank of the power supply system of the charging and swapping station is specified. This design targets battery replacement of pure electric bus in Youyi street. If there is an exception occurred, it will cause serious social impact and economic losses. The battery replacement of electric bus belongs to second order load, so it is necessary to adopt double-circuit power supply mode. In this way, in case of failure of one circuit, the other circuit can serve as backup to maintain normal power supply and ensure the practicability of power supply.

\subsubsection{High Voltage Distribution System}

According to the planning and design of power system in Dalian region, the charging and swapping station of Youyi Street uses $10 \mathrm{kV}$ double-circuit power supply, one of which comes from $10 \mathrm{kV}$ bus of $66 \mathrm{kV}$ substation in Youyi Street, whose cable adopts pipe laying, and the other comes from $10 \mathrm{kV}$ bus of Zhoushuizi $66 \mathrm{kV}$ substation.

(1) Selection of High-Voltage Switchgear

The $10 \mathrm{kV}$ high-voltage switch uses KYN type handcart cabinet, with 2 sides of incoming cabinet, metering box and PT lightning protection cabinet respectively. The circuit breaker of high-voltage cabinet selects vacuum circuit breaker to facilitate opening operation of subsequent modules. The rated current of incoming circuit breaker is $1250 \mathrm{~A}$. According to the short-circuit current value provided by the power system, the short-circuit current of the circuit breaker is $25 \mathrm{kA}$.

(2) Selection of High-Voltage Distribution Transformer

The side with higher charging voltage of electric vehicle in Youyi Street uses double circuit $10 \mathrm{kV}$ power inlet and is equipped with two distribution transformers with low no-load loss, so that each transformer can bear $1 / 2$ of the load under normal operation. The formula for calculating the charging capacity is:

$$
\mathrm{S}=\mathrm{P} /(\cos \varphi \times \eta)
$$




\subsection{System Design of Charging and Swapping Station}

\subsubsection{Charging System Scheme}

The charger of electric bus adopts storage batteries. The design scheme of charger platform chooses single box charging structure, as shown in the picture. The reason why single box charging is selected is that each box of battery pack is charged by one charger. The whole charging process can be controlled through the charging management system to ensure stable operation of the system during charging. The charging interface of the charger is connected to the monitoring network communication of the upper computer, so that the status of the charger can be obtained in real time. ${ }^{[6]}$

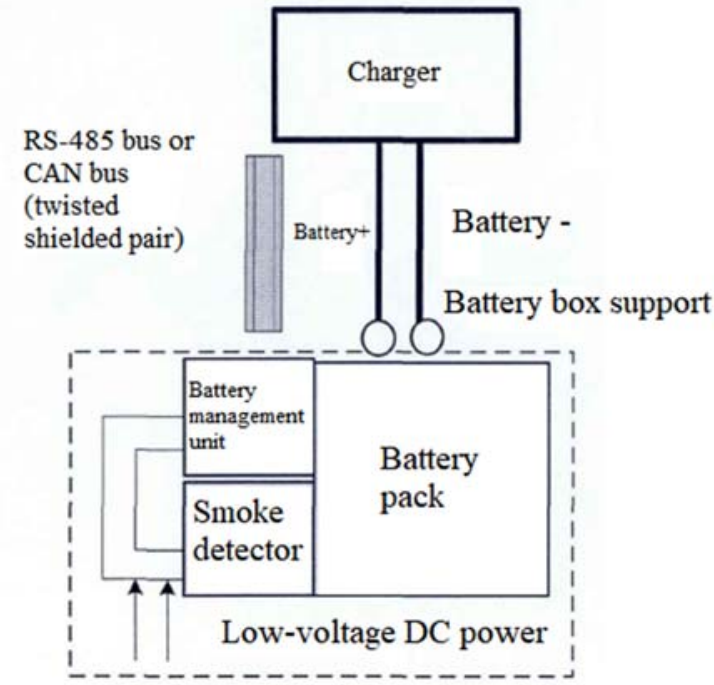

Fig 1 Structure Diagram of Single-box Charger and Charging Platform

\subsubsection{Schematic Diagram of Charger}

The design principle of the electric bus charger this time is shown in the figure. It is mainly divided into three parts, which include three-phase voltage source PWM rectifier, bidirectional DC/DC converter and filter. In normal operation, the input voltage of the three-phase network is rectified by a rectifier and is output in the form of direct current, which can be used as the direct current input of the power conversion circuit through the filter. This is because in this design, the three-phase rectifier can correct the power factor to ensure the minimum current harmonic on the power grid side. ${ }^{[7]}$

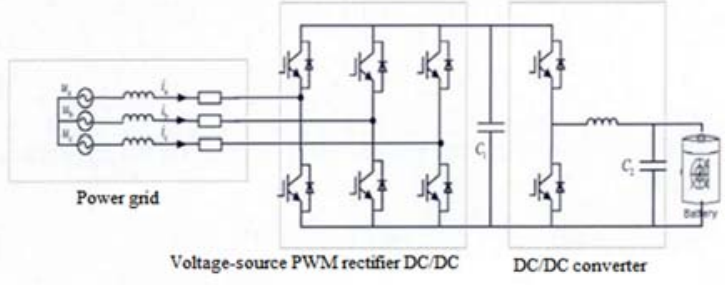

Fig 2 Topological Structure of Electric Bus Charger

\subsection{Swapping System Scheme}

\subsubsection{Design Scheme of Swapping System}

The battery replacement system of electric bus mainly unloads the battery that has run out of power from the bus, and places them on the battery support of the charger, and then replace the fully charged battery from the battery support to the electric bus, so that the bus can keep running. At present, there are 6 large boxes of battery packs and 4 small boxes of battery packs required by each electric bus, and they weigh $200 \mathrm{~kg}$ and $150 \mathrm{~kg}$ respectively. In the design, it needs to be taken into consideration that the battery replacement time of each electric bus should be less than the departure interval, which should be controlled within 10 minutes. If the battery pack is completely replaced manually during the swapping period, it is difficult to complete the battery replacement within the prescribed period. Therefore, an additional brake robot arm can be considered to realize the replacement during the design.

The title is set in bold 16-point Arial, justified. The first letter of the title should be capitalised with the rest in lower case. You should leave $35 \mathrm{~mm}$ of space above the title and $6 \mathrm{~mm}$ after the title.

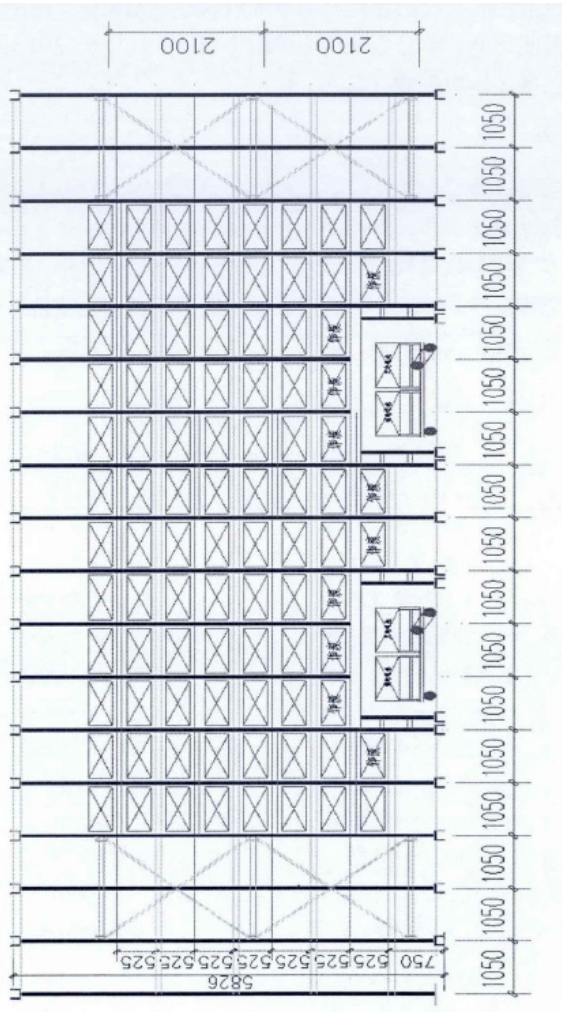

Fig 3 Structure Diagram of Battery Support

The high-rise battery support and the stacker constitute the current battery support storage area, and the specific parameters are shown in the figure. The operation of taking and storing batteries from the battery support can be completed through three-dimensional movement, and the monitoring system can monitor the whole process of replacement. The robot arm uses electromagnetic sucker to replace the battery box of the 
electric bus, which is mainly composed of a handcar, a tooling platform and an electrical control device.

\subsubsection{Implementation of the Swapping System}

In this design, the swapping system needs to take out the battery or put it into the battery support, and the swapping process will be monitored in real time by the monitoring device. For workers, they can capture the running state of the operating system in the swapping process, which can be divided into two parts for discussion. First, the battery needs to be placed on the battery support to access the battery. If the battery is found to be in a state of insufficient power during the system detection process, it will be charged on the support. If there is an exception occurred, it will be sent to the maintenance area, and be placed in the swapping system with the help of the robot arm and the stacker. There are two steps in the replacement. The stacker is responsible for removing the fully charged battery from the battery support and placing the battery to be charged on the battery support. It takes 5 minutes for the stacker to remove 2 small batteries and 3 large batteries from the battery support under the working condition. This process does not interfere with the operation of the robot arm, which will select the appropriate battery according to the position of the batteries of electric buses. The time consumed in the battery replacement process is less than 10 minutes. Therefore, the whole system only needs to modify the software program according to the vehicle type during the operation process and does not need to replace the hardware equipment. The specific replacement process is shown in the figure.

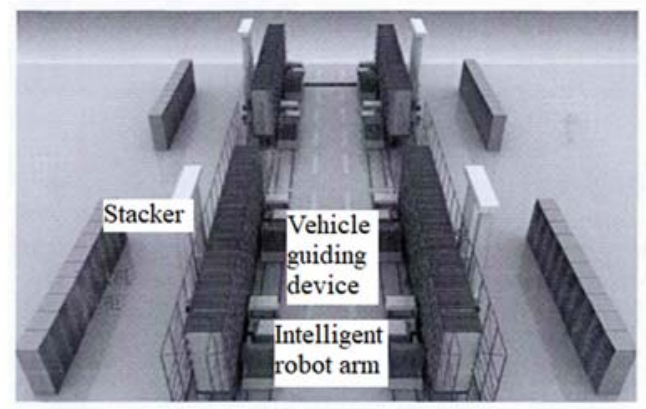

Fig 4 Overall Layout of Battery Replacement System

Secondly, the battery delivery also conforms to the flow chart shown below. When the bus to be charged enters the swapping station, it communicates with the warehouse management through the card reader to update the database information. The obtained vehicle type data and warehousing information are detected and monitored by the swapping program of the monitoring system during the whole process, and the system will decide whether there is a suitable battery available according to the vehicle type information. If so, the system will enter the battery replacement process.

(1) The rechargeable battery enters the charging station

The card reader will receive sequence information and coordinate information of batteries replaced and directly notify the owner to go to the designated position for battery replacement operation. The driver of the electric bus will arrive at the designated position according to the formal instructions. After the vehicle is fixed by the inhibiting device, the driver will open the battery cover through socket in the cab, and the staff will remove the battery of the electric bus according to the pre-set program by operating the manual assistant positioning device, and then put the removed battery on the battery support.

(2) Delivery process of fully charged batteries

After WMS enters the delivery subprogram, according to the preset algorithm, the background will select corresponding fully charged battery. Then the battery waits to be delivered, and the delivered battery will be placed on the anchorage device. The staff will operate the manual assisted positioning device to install the delivered battery to the vacant position. When the battery is installed, the driver only needs to press the Battery button to close the battery box. If the next battery needs to be replaced, start the above process all over again.

However, in the design, it is also necessary to consider the occasion that the battery meeting the requirements cannot be found. At this time, the card reader will inform the electric bus driver that he needs to pull over at the designated position, and can choose whether to wait for a certain period of time for the required battery to be fully charged before replacing it. While waiting, the bus driver will be informed by the broadcast to wait at the position of the corresponding battery.

\section{DESIGN OF PHOTOVOLTAIC ENERGY STORAGE SYSTEM FOR CHARGING AND SWAPPING STATION IN YOUYI STREET}

In recent years, China has vigorously promoted the generalization of new energy PV technologies. Dalian, as a model city, has applied new energy PV technology to the design of swapping stations, making full use of new photovoltaic energy, and making the original charging device more environmentally friendly, green and economical.

At present, the swapping station mainly uses electric supply as the main power source, and uses solar energy and energy storage batteries as auxiliary power source. To meet the daily supply of 50 electric buses, 30 battery packs need to be prepared, and each battery pack needs to be charged four times a day. Therefore, the swapping station needs to provide battery charging service for 120 times a day. In such case, the photovoltaic energy storage device can be used to reduce the charging costs at the ebb at night, so as to undertake the charging task of $5 \%$ of the electricity required by the whole swapping station every day. The photovoltaic energy storage system is mainly powered by the combination of solar photovoltaic and the energy storage device, and its total power supply can reach $800 \mathrm{kWh}$ in the application process of the photovoltaic energy storage device. 


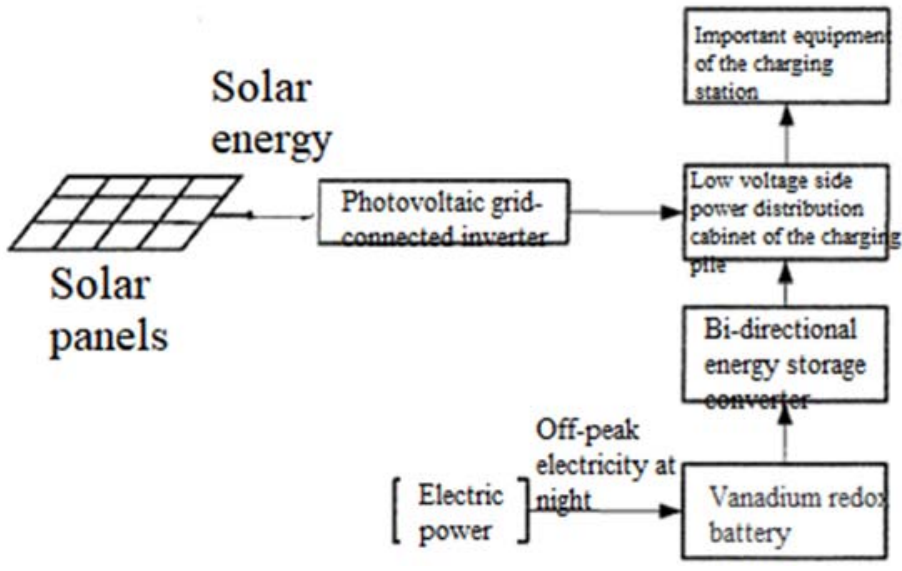

Fig 5 Photovoltaic Energy Storage System

Photovoltaic energy storage system mainly converts solar energy into electric energy through solar panels. The output direct current will be converted into AC voltage through the photovoltaic grid-connected inverter and sent into the low voltage side power distribution cabinet of the charging station. And the voltage value of its access point is $380 \mathrm{~V}$. The energy storage battery will be connected to the grid through the converter and the voltage value of its access point is $380 \mathrm{~V}$. The photovoltaic system is selected in this design because:

(1) The photovoltaic energy storage system can convert the original electric power charging into energy storage battery charging by means of a converter in the swapping station at night.

(2) During the daily peak hours of the charging and swapping station, the energy storage battery will convert the stored DC energy into AC energy through an inverter and connect it in parallel with the low-voltage busbar of the substation, thus supplying power to the battery during the peak hours.

(3) If there is a failure or problem in the electrical power in the swapping station on the day, the energy storage system can supply power to batteries of the whole station through UPS to reduce losses as much as possible.

The application of photovoltaic energy storage system in the design of charging and swapping station can effectively change the original use cost. According to estimation, if fixed swapping can be completed every day, the savings of the cost can reach up to 4,000 yuan, and the final annual savings of the cost can amount to 1.5 million yuan.

\section{Conclusions}

This design has fully considered the use demand of electric buses in Youyi Street of Dalian and determined to use the scheme of swapping as the main form and plug-in as the supplementary form, so as to make sure the bus can run all day long. Considering the demand of design and capacity of power consumption, the design of power distribution scheme selected $10 \mathrm{kV}$ dual power supply mode. The existence of backup power supply can enhance the power supply reliability of the system.
Secondly, the charging solution determined the appropriate charging strategy according to the working principle of the charger. Finally, each bus is equipped with 10 battery boxes, 30 packs of replacement batteries and 240 chargers, which can provide 120-180 charging services for the bus every day. Considering weight and time factors in the swapping process, a two-step replacement method is finally used, and the battery is accessed by means of a stacker and a robot arm. This design can complete all operations of battery replacement and battery storage within 10 minutes, thus improving the battery replacement efficiency. Considering the charging cost factor, a photovoltaic energy storage system is also added in the design, which uses stored electric energy for charging at the ebb at night, and the battery discharge provides electric energy for the whole station during the day.

\section{References}

1. Oliveira Farias Héricles Eduardo,Sepulveda Rangel Camilo Alberto,Weber Stringini Leonardo,Neves Canha Luciane,Pegoraro Bertineti Daniel,da Silva Brignol Wagner,Iensen Nadal Zeno. Combined Framework with Heuristic Programming and RuleBased Strategies for Scheduling and Real Time Operation in Electric Vehicle Charging Stations[J]. Energies,2021,14(5).

2. CheikhMohamad Saleh,Sechilariu Manuela,Locment Fabrice,Krim Youssef. PVPowered Electric Vehicle Charging Stations: Preliminary Requirements and Feasibility Conditions[J]. Applied Sciences,2021,11(4)

3. Balacco Gabriella,Binetti Mario,Caggiani Leonardo,Ottomanelli Michele. A Novel Distributed System of e-Vehicle Charging Stations Based on Pumps as Turbine to Support Sustainable Micromobility[J]. Sustainability,2021,13(4).

4. Wang Xiaohui,Zheng Xiaokun,Liang Xiao. Charging Station Recommendation for Electric Vehicle Based on Federated Learning[J]. Journal of Physics: Conference Series,2021,1792(1) 
5. Sheng Wang, Hao Wu. Summary of Intelligent Charging Station Management Platform[J]. Scientific Journal of Intelligent Systems Research,2021,3(2).

6. Zhao Xuliang,Xue Jiguang,Wu Tong,Xue Hong,Dong Sitong,Liu Yan. Electric vehicle dispatching in smart charging station: a pricing strategy[J]. IOP Conference Series: Earth and Environmental Science,2021,675(1).

7. Anzola Jon,Aizpuru Iosu,Arruti Asier. Partial Power Processing Based Converter for Electric Vehicle Fast Charging Stations[J]. Electronics,2021,10(3). 